\title{
Hyposensibilisierung auch über Kreuz?
}

\author{
Viele Pollenallergiker leiden auch unter einer Nahrungsmittelallergie, \\ ein typisches Beispiel ist die Kreuzreaktivität gegenüber Birkenpollen \\ und Apfel- oder Haselnussallergenen. Schon lange wird diskutiert, ob \\ eine spezifische Hyposensibilisierung mit Baumpollen auch die paral- \\ lele Nahrungsmittelallergie positiv beeinflussen kann.
}

- in Allergologenteam aus Bern in der - Schweiz führte im Rahmen einer prospektiven kontrollierten Studie bei 15 von 27 Birkenpollenallergikern mit einem oralen Allergiesyndrom durch Apfel oder Haselnuss eine subkutane spezifische Immuntherapie (SIT) mit Birkenpollenextrakt durch. Die übrigen Patienten dienten als Kontrollgruppe. Nach einem Jahr erfolgte eine orale Provokationstestung mit ansteigenden Dosen von frischen Äpfeln oder Haselnüs- sen ( 1 bis $128 \mathrm{~g}$ ) bis zum Auftreten von Symptomen wie Heiserkeit, Husten oder Gesichtserythem. Parallel wurden ein Pricktest mit Birkenpollen, Apfel und Haselnuss durchgeführt sowie spezifisches IgE, IgG und $\mathrm{IgG}_{1}$ für die Allergene gemessen.

Nach einem Jahr konnten im Vergleich zum Studienbeginn 13 von 15 SIT-Patienten eine doppelt bis dreifach so große Dosis Äpfel oder Haselnüsse vertragen, während dies in der Kontroll- gruppe nur bei einem Teilnehmer zu beobachten war. Die Gesamtmenge an vertragenem Apfel bzw. an vertragenen Haselnüssen blieb aber gering. Im Serum der Patienten der SIT-Gruppe konnte ein signifikanter Anstieg von spezifischen $\mathrm{IgG}_{4}$-Antikörpern auf rBet $\mathrm{v} 1$ festgestellt werden.

Fazit: In dieser Studie mit kleiner Patientenzahl beeinflusste die SIT mit Birkenpollen auch das parallel bestehende durch Apfel oder Haselnuss ausgelöste orale Allergiesyndrom positiv. Der Effekt ist jedoch so gering, dass er für die Patienten in der Regel keine Lockerung ihrer diätetischen Restriktion bedeutet. $\quad f k$

Bucher $\mathbf{X}$ et al. Effect of tree pollen specific, subcutaneous immunotherapy on the oral allergy syndrome to apple and hazelnut. Allergy 2004; 59: 1272-6

\section{Neue Walnussallergene identifiziert}

\begin{abstract}
Allergien gegen Walnüsse gehören mit einer Prävalenz von 0,2-0,7\% zu den wichtigsten Baumnussallergien. Bisher waren zwei Majorallergene bekannt, eine italienische Arbeitsgruppe identifizierte jetzt weitere Walnussallergene.
\end{abstract}

\begin{abstract}
A llergologen aus Mailand und Turin führten mit den Seren von 46 Patienten, die unter einem oralen Allergiesyndrom oder systemischen Reaktionen nach Zufuhr von Walnüssen litten, Immunoblots mit Walnussextrakt durch. Anschließend wurden die identifizierten Allergene per HPLC gereinigt und durch Sequenzierung näher charakterisiert.

Als einziges Majorallergen konnten die Forscher ein Lipidtransferprotein mit einer Masse von $9 \mathrm{kD}$ identifizieren - IgE-Antikörper gegen dieses Protein waren im Serum von 36 der 46 Patienten $(78,2 \%)$ nachweisbar. Darüber hinaus wurden bei einigen Patienten $(21,7 \%)$ noch zwei weitere Antikörper gegen 9-kD-Allergene identifiziert, die der Proteinklasse der Viciline zugeordnet wurden. Viciline fungieren als Samenspeicherproteine.

Die drei neu gefundenen Allergene ergänzen die bisher bekannte Palette
\end{abstract}

von Walnussallergenen: Jug r 1, ein 2SAlbumin, und Jug r 2, ein Vicilin-ähnliches Protein. Das 9-kd-Lipidtransfer-

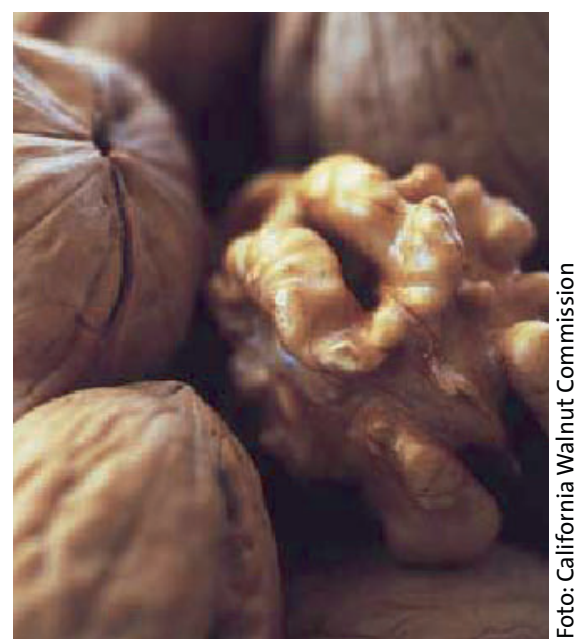

Bei den Hauptallergenen der Walnuss (Juglans regia) handelt es sich um Samenspeicher- und Lipidtransferproteine. protein wurde als neues Majorallergen vom Allergen Nomenclature Sub-Committee der International Union of Immunological Societies als Jug r 3 registriert.

In der Studie ergab sich für Jug r 3 eine IgE-Kreuzreaktivität mit dem Majorallergen des Pfirsichs, ebenfalls ein Lipidtransferprotein. Alle IgE-bindenden Epitope des Walnussallergens waren auch beim Pfirsichallergen nachweisbar - das Pfirsichprotein weist allerdings noch weitere IgE-Bindungsstellen auf. Tatsächlich waren die meisten Patienten auch primär gegen Pfirsiche sensibilisiert und erst sekundär gegen Walnüsse. Eine Birkenpollenallergie lag bei den gegen Jug r 3 sensibilisierten Patienten nicht vor.

Fazit: Ein 9-kD-Lipidtransferprotein wurde als neues Hauptallergen der Walnuss identifiziert und als Jug r 3 registriert. Bei dieser Allergie ist ein Pfirsichprotein das primäre Allergen, eine Pollenallergie, z. B. gegen Birke, lag bei den untersuchten Patienten nicht vor. $\quad b k$

Pastorello EA et al. Lipid transfer protein and vicilin are important walnut allergens in patients not allergic to pollen. J Allergy Clin Immunol 2004; 114: 908-14 